\title{
ESTUDO DE CASO SOBRE A INSERÇÃO DE PESSOAS COM DEFICIÊNCIA NUMA ORGANIZAÇÃO DE GRANDE PORTE
}

\author{
Adamir Moreira Assis \\ Universidade Federal de São João del-Rei, São João del-Rei, MG / Brasil \\ adamir.assis@yahoo.com.br \\ Maria Nivalda Carvalho-Freitas \\ Universidade Federal de São João del-Rei, São João del-Rei, MG / Brasil \\ nivalda@ufsj.edu.br
}

http://dx.doi.org/10.1590/1413-2311022201342126

Recebido em 18/06/2013

Aprovado em 06/12/2013

Disponibilizado em 01/08/2014

Avaliado pelo sistema double blind review

Revista Eletrônica de Administração

Editor: Luís Felipe Nascimento

ISSN 1413-2311 (versão on-line)

Editada pela Escola de Administração da Universidade Federal do Rio Grande do Sul.

Periodicidade: Quadrimestral

Sistema requerido: Adobe Acrobat Reader.

\section{RESUMO}

O processo de inclusão de pessoas com deficiência nas organizações tem sido permeado por dificuldades, seja para contratar, valorizar ou reter esses profissionais. Apesar do impositivo legal, o qual exige há mais de 20 anos a contratação de pessoas com deficiência pelas empresas privadas, nem todas as organizações conseguiram se adequar a ele. Foi realizado um estudo de caso numa organização de grande porte, a qual possui um programa de inclusão com o intuito de se conhecer a percepção das pessoas com deficiência e gestores sobre o programa. Participaram da amostra 291 pessoas com deficiência, 198 gestores e um profissional de recursos humanos $(\mathrm{RH})$. Adotaram-se métodos de pesquisa quantitativo (survey de desenho transversal) e qualitativo, cujos dados foram coletados por meio de observação, pesquisa de documentos e entrevistas semiestruturadas e submetidos à análise de conteúdo. A organização pesquisada, situada neste contexto histórico de transformação, está realizando um movimento para se adequar e se tornar uma empresa inclusiva. Ela vivencia a fase de integração, na qual as pessoas, mediante sua competência e adaptação, têm mostrado que são capazes de produzir. Mudanças têm sido percebidas nas práticas e valores da organização: sua evolução vai da exclusão rumo à inclusão. É constatado que, independente do porte e segmento da organização: é possível fazer a inserção de pessoas com deficiência; é vivida uma fase de transição para um modelo realmente inclusivo (a sociedade e as organizações passam por essa transição); há necessidade de constante investimento na reflexão e informação sobre as deficiências, para que se diminuam o preconceito e a exclusão social.

Palavras-chave: inclusão; pessoas com deficiência; mercado de trabalho. 


\title{
CASE STUDY ON THE INTEGRATION OF PEOPLE WITH DISABILITIES ON A
}

\section{LARGE ORGANIZATION}

\begin{abstract}
The inclusion of people with disabilities in organizations has been a difficult process, in terms of hiring those professionals, enhancing their performance or even retaining them. Despite the imposing statutory, which hasbeen demanding, for over 20 years, that private companies must hire people with disabilities, not all organizations have fulfilled it. This research was carried out in a large organization, which has an inclusion program with the purpose of knowing the perception of people with disabilities and managers about the program. 291 disabled people, 198 managers and one human resource (HR) professional participated in the sample. Quantitative and qualitative research methods (cross-sectional survey) were used. The case study was conducted in an organization which is a movement to transform itself in an inclusive company. Currently experiencing the integration phase, in which the people, through their competence and adaptation, have shown that they are capable of producing. Changes have been noticed in the practices and values of the organization: its evolution will exclusion towards inclusion. It appears that, regardless the organization's size and sector, it is possible to make the inclusion of persons with disabilities; this organization has experienced a transitional period, changing to a truly inclusive model (society and organizations go through this transition); and there is a need for constant investment in reflection and information on disabilities, in order to reduce prejudice and social exclusion.
\end{abstract}

Keywords: inclusion; people with disabilities; labor market.

\section{ESTUDIO DE CASO SOBRE LA INSERCIÓN DE PERSONAS CON DEFICIENCIA EN UNA GRAN ORGANIZACIÓN}

\begin{abstract}
RESUMEN
El proceso de inclusión de personas con deficiencia en las organizaciones ha sido traspasado por dificultades para contratar, valorizar o retener a esos profesionales. A pesar del impositivo legal que exige, hace más de 20 años, la contratación de esas personas por las empresas privadas, no todas consiguieron adecuarse al mismo. Fue realizado un estudio de caso en una gran organización que posee un programa de inclusión con el intuito de conocer la percepción de personas con deficiencia y gestores sobre el programa. En la muestra participaron 291 personas con deficiencia, 198 gestores y un profesional de recursos humanos (RH). Se adoptaron métodos de investigación cuantitativo (survey de diseño transversal) y cualitativo, cuyos datos fueron recolectados por medio de observación, investigación de documentos y entrevistas medio estructuradas y sometidos al análisis de contenido. La organización investigada, situada en este contexto histórico de transformación, está realizando un movimiento para adecuarse y convertirse en una empresa inclusiva. La misma vive la fase de integración, en la cual las personas, mediante su competencia y adaptación, han mostrado que son capaces de producir. Cambios han sido percibidos en las prácticas y valores de la organización: su evolución va de la exclusión rumbo a la inclusión. Se constata que, independiente del porte y segmento de la organización, es posible hacer la inserción de personas con deficiencia; es vivida una fase de transición para un modelo realmente inclusivo (la sociedad y las organizaciones pasan por esa transición); hay necesidad de constante
\end{abstract}


Estudo de caso sobre a inserção de pessoas com deficiência numa organização de grande porte

inversión en la reflexión e información sobre las deficiencias, para que se disminuyan el prejuicio y la exclusión social.

Palabras Clave: inclusión; personas con deficiencia; mercado de trabajo.

\section{INTRODUÇÃO}

Atualmente, profissionais e pesquisadores de diversas áreas têm discutido muito sobre o tema da inclusão. Mas por que se fala tanto em inclusão? Por que existe esse fenômeno? É falada inclusão porque existem pessoas que, por diferentes motivos, encontram-se alocadas numa categoria de excluídos. Essa categorização carrega consigo uma conotação de julgamento, havendo estigma e preconceito contra essa categoria, que é considerada como minoria, como as pessoas com deficiência (BARTALOTTI, 2006; NERI; PINTO, SOARES e COSTILHA, 2003; SHANNON; TANSEY e SCHOEN, 2009).

Assim, o processo de inclusão é a soma de esforços dos indivíduos (ainda excluídos) e da sociedade para equacionar problemas, encontrar soluções e buscar a igualdade de oportunidades para todos. Para Sassaki (2006), é necessário um processo envolvendo esforços mútuos, em que a sociedade precisaria se adaptar para incluir e, simultaneamente, as pessoas se preparariam para assumir seus papéis na sociedade. Stainback e Stainback (1999) chamam a atenção para a aceitação das diferenças e colocam que a inclusão não é uma ação ou conjunto de ações, mas uma atitude, uma convicção. Ou seja, para haver inclusão, é necessário um processo de igualdade de oportunidades e de direitos para todos.

Ao considerar o mercado de trabalho, Neri et al. (2003) afirmam que, no início do milênio, apenas 2,05\% do total de trabalhadores brasileiros eram pessoas com deficiência, sendo que 29,05\% deles viviam em situação de miséria e 27,61\% não possuíam nenhuma escolaridade. Resultados apresentados pela Relação Anual de Informações Sociais (RAIS) revelam que, do total de vínculos empregatícios ativos no final de 2010, apenas 0,7\% eram de pessoas com deficiência (MTE, 2010).

Pesquisa realizada em 2010 pelo Instituto Ethos sobre o perfil social, racial e de gênero das 500 maiores empresas do Brasil e suas ações afirmativas revela que vem crescendo o número de organizações que têm adotado a inclusão de pessoas com deficiência em seus quadros. Nesse grupo seleto, em 2003, 32\% das empresas tinham pessoas com deficiência em seus quadros, sendo que esse número subiu para 41\% em 2005, 67\% em 2007 e $81 \%$ em 2010. Ainda na referida pesquisa do Instituto Ethos, em 2010, apenas 1,5\% do quadro de empregados eram compostos por pessoas com deficiência e $81 \%$ das empresas que compuseram a amostra tinham mais de 1.000 empregados.

REAd | Porto Alegre - Edição 78 - N 2 - maio/agosto 2014 - p. 496-528 
Como demonstrado, apesar de ter havido um aumento no número de empresas que estão contratando pessoas com deficiência, ainda não é atendido o mínimo exigido por lei. $\mathrm{O}$ estudo do Instituto Ethos (2010) revela grande contraste entre a realidade do mercado de trabalho e o que prevê a legislação. É proibida, pela Constituição Federal, qualquer discriminação para admissão e remuneração em razão de deficiência e ela garante a reserva de vagas na administração direta e indireta às pessoas com deficiência. Além disso, a Lei 8.213, de 1991 (BRASIL, 1991), conhecida como Lei de Cotas, obriga as empresas com 100 ou mais empregados a preencherem de 2 a $5 \%$ de suas vagas com pessoas reabilitadas ou que possuam deficiência. O Artigo 93 da Lei 8.213 (BRASIL, 1991) prevê que empresas que reúnam entre 100 e 200 empregados tenham $2 \%$ de seus cargos ocupados com pessoas com deficiência; de 201 a 500, 3\%; de 501 a 1.000, 4\%; e acima de $1.001,5 \%$.

Apesar de a Lei de Cotas ter sido publicada em 1991, ou seja, há mais de 20 anos, ela não tem sido cumprida por todas as organizações, demonstrando a dificuldade no cumprimento da Lei, inclusive nas maiores organizações do Brasil.

Mas se a Lei determina as cotas para contratação de pessoas com deficiência, então por que tem sido tão difícil fazer a inclusão? Se há um total de $24 \%$ de pessoas com deficiência no Brasil, conforme apontam os dados do IBGE em 2010, por que apenas 2,05\% delas estão inseridas no mercado de trabalho?

As causas são múltiplas e complexas. Apesar do avanço das pesquisas sobre inserção na última década, há necessidade de constante investigação sobre esse tema tanto para elucidar as causas dessa dificuldade como para também vislumbrar estratégias que facilitem a equidade e a inclusão (NERI et al., 2003).

Sobre esse aspecto, é possível observar que o maior problema enfrentado pelas pessoas com deficiência não é a ausência de leis, tampouco legislações aplicáveis aos casos concretos. A grande dificuldade está exatamente na eficácia das normas existentes, ou seja, na obediência às leis e sua referida execução. Teoricamente, o Brasil dispõe de uma das mais avançadas legislações mundiais de proteção e apoio às pessoas com deficiência, mas há grande lacuna na sua aplicabilidade, ainda arraigada de preconceitos e barreiras à sua integração no mercado de trabalho (NERI et al., 2003).

Os pesquisadores que têm se dedicado ao estudo da inclusão de pessoas com deficiência são unânimes em apontar as dificuldades decorrentes desse processo. Existem as barreiras funcionais, tais como arquiteturas inadequadas e dificuldade de acesso ao local de trabalho e ao transporte, por exemplo, mas também há dificuldade de encontrar pessoas com 
Estudo de caso sobre a inserção de pessoas com deficiência numa organização de grande porte

deficiência qualificadas, visto que a escolaridade desse grupo tende a ser mais baixa (SUZANO et al., 2008; OLIVEIRA, 2008; INSTITUTO ETHOS, 2010; NERI et al., 2003), o que as leva a ter empregos de baixo nível e de baixo rendimento (OIT, 2007), além de existir uma barreira mais séria a ser transposta, que é a barreira social (PASTORE, 2000; SHANNON et al., 2009). Esta pode ser observada no constante preconceito do qual esse grupo de pessoas é vítima, dificultando sua contratação e sua adaptação no ambiente de trabalho.

Contudo, realizar de fato a inclusão das pessoas com deficiência no complexo processo produtivo ainda é um desafio, uma vez que existem preconceitos em relação à sua capacidade contributiva e participativa num contexto competitivo que retrata o atual perfil de grande parte das empresas. Esse preconceito está relacionado ao desconhecimento acerca das reais possibilidades e limitações de a pessoa com deficiência ser inserida como agente ativo do processo de produção, pois, desde que lhe sejam dadas as oportunidades, ela pode desenvolver todo o seu potencial (CARVALHO-FREITAS, 2007; NERI et al., 2003).

Diante desse cenário de dificuldades para se fazer a inclusão, apesar de o amparo legal existir há mais de 20 anos, a presente pesquisa teve por objetivo investigar uma organização de grande porte, do setor de mineração, para conhecer como ela está realizando a inclusão, as estratégias utilizadas e os desafios vivenciados. Como objetivos específicos, procurou-se: conhecer o histórico do programa de inclusão e as fases vivenciadas por esta organização; identificar a percepção das pessoas com deficiência e gestores sobre o programa de inclusão. Outros estudos de caso já foram realizados (CARVALHO-FREITAS, 2009; ÁVILA-VITOR, 2011; RIBEIRO e RIBEIRO, 2009; DAUFEMBACK, 2009). No entanto, no setor de mineração, que traz em sua própria condição de trabalho inúmeros desafios, nenhum estudo de caso foi identificado.

O presente artigo apresenta inicialmente as dificuldades registradas pelos pesquisadores da área para se fazer a inclusão, o que é confirmado pelos dados estatísticos revelando a exclusão das pessoas com deficiência. $\mathrm{Na}$ sequência, são apresentadas as fases históricas vivenciadas pelo movimento da inclusão, seguindo-se da metodologia utilizada, a qual envolveu a utilização de uma abordagem quantitativa e qualitativa. Após, apresenta-se a análise e discussão dos dados e considerações finais.

\section{REFERENCIAL TEÓRICO}

REAd | Porto Alegre - Edição 78 - N² 2 - maio/agosto 2014 - p. 496-528 
Embora termos como inserção, integração e inclusão venham sendo utilizados em algumas circunstâncias como sinônimos, essas palavras têm sentidos diferentes. De acordo com Cunha (1982), no Dicionário Etimológico, são encontrados como significado para a palavra inserir os termos "introduzir, meter em e intercalar". Ou seja, no contexto deste trabalho, inserir seria a pura e simples ação de introduzir pessoas com deficiência no mercado de trabalho. Para Sassaki (2006), a integração seria o esforço de inserir na sociedade pessoas com deficiência que estejam preparadas de acordo com os padrões sociais vigentes, o que pressupõe um esforço unilateral de reabilitação e inserção para superar as barreiras que possam existir. Já o termo incluir, conforme Cunha (1982), significa "abranger, compreender, envolver". Ou seja, a inclusão envolve um esforço da sociedade para garantir a igualdade de oportunidades, a adequação dos ambientes, as condições e os instrumentos de trabalho para “abranger" e "envolver" todas as pessoas.

Quando são analisados os próprios termos utilizados para se referir ao grupo de pessoas com deficiência, são percebidas certa discriminação e ações diferenciadas na forma de lidar com essas pessoas. Historicamente, eram usadas palavras negativas para qualificar pessoas com problema de surdez, atraso mental, cegueira etc. Assim, termos pejorativos, como aleijado e retardado, eram culturalmente aceitos e empregados. Estudos mais recentes procuram retirar o foco da "deficiência", concentrando-o na "pessoa". O termo "portador" é contestado por alguns autores, como Fávero (2004), para quem a deficiência não pode ser traduzida como imperfeição ou defeito, porque não existe perfeição ou ausência total de defeitos em qualquer ser humano. Já o termo "portador de necessidades especiais", em alguns momentos também empregado, é questionado por outros autores, pois todas as pessoas têm algum tipo de necessidade especial. Esse é um termo abrangente e inclui, além de pessoas com deficiência, diabéticos e idosos, entre outros. Portanto, neste trabalho, será utilizado o termo pessoa com deficiência, o qual tem sido utilizado em artigos nacionais e internacionais.

No âmbito das discussões sobre deficiência, Neri et al. (2003) afirmam que existem diversas definições internacionais de deficiência. A Classificação Internacional de Deficiência, Incapacidades e Desvantagens (CIDID - 1989) tem um conceito mais restrito de deficiência, caracterizando-a como a "perda ou anormalidade" de estrutura psicológica, fisiológica ou anatômica. Uma definição mais ampla de deficiência é a expressa pela Convenção de Guatemala, que considera como deficiência "a restrição física, mental ou sensorial, de natureza permanente ou transitória, que limita a capacidade de exercer uma ou mais atividades essenciais da vida diária, causada ou agravada pelo ambiente econômico e 
Estudo de caso sobre a inserção de pessoas com deficiência numa organização de grande porte

social". Já Carvalho-Freitas (2007) conceitua deficiência como o "resultado da articulação entre a condição biológica e as contingências históricas, sociais e espaciais, o qual poderá significar uma maior ou menor possibilidade de inserção ou discriminação das pessoas com deficiência" (p. 24).

A preocupação com a inclusão das pessoas com deficiência no mercado formal de trabalho teve início na década de 70 do século XX, na qual a Organização das Nações Unidas (ONU) e outros órgãos internacionais começaram a se preocupar com os direitos das pessoas com deficiência (PASTORE, 2000). Assim, é possível perceber que os estudos sobre a gestão da diversidade são recentes. Embora tenha havido pesquisas sobre a deficiência e inserção no trabalho nas últimas duas décadas, foi constatado que, a partir da Lei de Cotas, houve aumento dos estudos nessa área (SUZANO et al., 2008).

De acordo com Bartalotti (2006), de maneira geral, essa parcela da população está precariamente incluída no campo da saúde, da educação, do trabalho e dos direitos sociais. Além das barreiras funcionais que dificultam a inserção das pessoas com deficiência, outro grave obstáculo tem origem na sociedade, sendo decorrente de barreiras sociais. Serrano e Brunstein (2008) acrescentam, na discussão sobre as dificuldades de inserção, que o comportamento das organizações varia desde a segregação até a falta de reconhecimento de sua capacidade laborativa.

Ao analisar a evolução histórica do movimento de inclusão de pessoas com deficiência, é percebido que a violência e a discriminação foram mais acentuadas no passado. A partir das últimas décadas do século XX, têm ocorrido um avanço na garantia dos direitos e maior inclusão dessas pessoas na sociedade. De acordo com Sassaki (2006), ao analisar a inserção das pessoas com deficiência no mercado de trabalho, são observadas diferentes fases que vão desde a exclusão, passando pela segregação e chegando à integração e inclusão de fato.

Na fase da exclusão, a pessoa com deficiência não tinha acesso ao mercado de trabalho. Ela era vista pela sociedade como incapaz, inválida e sem condições de trabalhar. Essa fase é percebida no Período Clássico, no início do século XX e, mais recentemente, quando se observa sua exclusão devido à falta de reabilitação física e profissional das pessoas com deficiência, assim como à falta de apoio da sociedade para incluir essas pessoas.

A fase da segregação é caracterizada por sentimentos paternalistas, como o de caridade, em que se acreditava que essas pessoas deveriam ser segregadas em instituições específicas, ou, se inseridas no trabalho, somente alguns postos de trabalho eram mais 
adequados para elas. É uma fase marcada pelo surgimento de instituições filantrópicas para apoio a essas pessoas, pelos subempregos e estagnação profissional. Essa fase também coexiste com as demais fases nos dias atuais.

$\mathrm{Na}$ fase da integração, as pessoas com deficiência são incluídas no mercado de trabalho mediante sua reabilitação física e profissional. Essa prática teve maior impulso na década de 1980 com o surgimento da luta pelos direitos das pessoas com deficiência. Praticamente, não há adequação das empresas ou da sociedade. É a própria pessoa que se adéqua à realidade organizacional. Nessa fase, pode faltar reconhecimento das pessoas com deficiência e de sua capacidade laboral, bem como oportunidade de crescimento.

\begin{abstract}
A integração tinha e tem o mérito de inserir a pessoa com deficiência na sociedade, sim, mas desde que ela esteja de alguma forma capacitada a superar as barreiras físicas, programáticas e atitudinais nela existentes. Sob a ótica dos dias de hoje, a integração consistiu em um esforço unilateral tão somente da pessoa com deficiência e seus aliados (a família, a instituição especializada e algumas pessoas da comunidade que abracem a causa da inserção social), sendo que estes tentam torná-la mais aceitável no seio da sociedade. Isto reflete o ainda vigente modelo médico da deficiência (SASSAKI, 2006, p. 33).
\end{abstract}

Já na fase da inclusão, a sociedade e as organizações precisam se adequar para acolher as pessoas com deficiência e permitir que elas tenham condições de desempenhar um bom trabalho. Nessa fase, as organizações se adéquam, modificam suas instalações e instrumentos de trabalho, reconhecem o potencial das pessoas com deficiência, cuidam de suas carreiras e as tratam com respeito. Essa fase é recente e vem sendo praticada em pequena escala por algumas empresas. Sassaki (2006) aponta alguns fatores internos que facilitam a inclusão da pessoa com deficiência, assim como facilitam também o trabalho: garantia de acessibilidade ao local de trabalho; adaptação de aparelhos, máquinas, ferramentas e equipamentos; adaptação de procedimentos de trabalho; implantação de programas de integração e treinamento adequados às pessoas com deficiência; revisão da filosofia da empresa para que garanta igualdade de oportunidades e valorização do potencial de todas as pessoas; criação de empregos a partir de cargos já criados; realização de sensibilização para chefias e colegas de trabalho; e aquisição de produtos de tecnologia assistiva que facilitem o desempenho profissional de empregados com deficiência.

Nessa perspectiva, o paradigma da inclusão é caracterizado pelo modelo social da deficiência, ou seja, a sociedade é que precisa se adequar para receber as pessoas, e não o contrário. De acordo com a estrutura da sociedade, ela pode criar situações que colocam as REAd | Porto Alegre - Edição 78 - N 2 - maio/agosto 2014 - p. 496-528 
Estudo de caso sobre a inserção de pessoas com deficiência numa organização de grande porte

pessoas com deficiência em desvantagem ou incapacidade de exercerem seus papéis sociais. Assim, por exemplo, ambientes sem acessibilidade adequada, políticas discriminatórias, preconceito, desinformação e exagero nos pré-requisitos para se trabalhar são elementos que podem dificultar ou impedir a pessoa com deficiência de se incluir no mercado de trabalho. Para Sassaki (2006), a sociedade é que precisa mudar e se adequar para que haja a inclusão.

Cabe, portanto, à sociedade eliminar todas as barreiras arquitetônicas, programáticas, metodológicas, instrumentais, comunicacionais e atitudinais para que as pessoas com deficiência possam ter acesso aos serviços, lugares, informações e bens necessários ao seu desenvolvimento pessoal, social, educacional e profissional (p. 45).

Carvalho-Freitas e Marques (2010) realizaram pesquisa em empresas brasileiras consideradas socialmente responsáveis, para investigar a forma como a deficiência era vista pelos gestores e as ações de adequação das práticas de trabalho. O universo da pesquisa foi constituído de 147 empresas que divulgaram seu balanço no Instituto Brasileiro de Análises Sociais e Econômicas (IBASE). Participaram da amostra 18 empresas que aceitaram fazer parte da pesquisa. A visão dos gestores sobre a deficiência identificada foi bastante diversificada, demonstrando que os modelos de interpretação oriundos de períodos históricos diversos ainda permanecem na atualidade. Ou seja, há crença de que a deficiência é um desvio da normalidade, existem gestores que acreditam numa origem espiritual da deficiência e prevalece, ainda, o grupo que acredita nos pressupostos da inclusão. Apesar de o grupo de empresas pesquisadas fazer parte das empresas socialmente responsáveis e de a maioria das empresas já trabalharem com contratação de pessoas com deficiência há vários anos, as pessoas ainda têm dúvidas sobre o processo de inserção e gestão do trabalho dessas pessoas. Foi constatado, também, que existe uma tendência geral das empresas em realizarem ações para adequação das condições de trabalho e predomínio de pouca concordância em relação à sensibilização e adequação das práticas de recursos humanos (RH). A hipótese levantada por Carvalho-Freitas e Marques (2010) é que as pessoas tendem a acreditar que apenas a adequação do ambiente e dos instrumentos de trabalho assegure a inserção, tendo dúvidas quanto à necessidade de práticas de sensibilização e procedimentos de $\mathrm{RH}$.

Embora haja visões diferentes sobre as concepções de deficiência ${ }^{1}$, não foi encontrada entre esses grupos diferença sobre as ações de adequações das condições e práticas de

\footnotetext{
${ }^{1}$ Concepções de deficiência são modos de pensamento construídos ao longo da história, que expressam as crenças das pessoas sobre a deficiência. São estruturadas a partir das matrizes de interpretação da realidade, ou seja, do modo como se vê e se lida com a realidade (Carvalho-Freitas \& Marques, 2007).
}

REAd | Porto Alegre - Edição 78 - N 2 - maio/agosto 2014 - p. 496-528 
trabalho. Quando é analisado o contexto atual de pressões legais, sociais e do interesse das empresas em serem consideradas socialmente responsáveis, é percebido que a inserção de pessoas com deficiência está ocorrendo nas empresas pesquisadas de forma não-estruturada.

Em um estudo realizado numa grande empresa do setor de prestação de serviços financeiros com mais de mil funcionários com deficiência, foi identificada a importância das ações de sensibilização e adaptações das condições de trabalho para a gestão da diversidade. Foi constatada nessa pesquisa que a concepção baseada na inclusão estava relacionada positivamente com as ações de sensibilização e com as práticas de RH, e vice-versa. Essa é uma constatação importante e que tem múltiplas repercussões, revelando, também, a relevância das ações de sensibilização e práticas de RH como pilares fundamentais para influenciar na acessibilidade e na concepção de inclusão. Além disso, foi encontrada uma relação positiva entre ações de sensibilização e benefícios de contratação, e vice-versa. Apesar de ser uma empresa com muitas pessoas inseridas e ser referência em inclusão, foi percebida a insatisfação das pessoas com deficiência com seu crescimento profissional. Outra constatação nessa pesquisa foi a correlação negativa entre práticas de RH e percepção de necessidade de treinamento, ou seja, quanto menos adequação das práticas de RH, maior é a percepção de necessidade de treinamento (CARVALHO-FREITAS, 2009).

As pesquisas realizadas nos últimos anos sobre as concepções de deficiência têm constatado a prevalência da concepção baseada nos pressupostos da inclusão embora haja a coexistência das diferentes concepções de deficiência (LARA; ÁVILA e CARVALHOFREITAS, 2008; CARVALHO-FREITAS e MARQUES, 2009, 2010; BRITE, 2009; CARVALHO-FREITAS, 2009; CARUSO, 2012).

No Brasil, a discussão e as leis sobre inclusão são relativamente recentes. Será necessário certo tempo para superar os séculos de exclusão e desequilíbrio social e mudar a cultura organizacional, pois as empresas ainda demoram um pouco a encontrar esse caminho para a inclusão e a modificação de sua cultura (IGNARRA; CONTRI e BATHE, 2009).

Por outro lado, os programas de administração da diversidade, quando bem implantados, podem melhorar o desempenho da organização, criar uma cultura de maior respeito e valorização das diferenças individuais, geram alto nível de envolvimento por parte dos empregados. Grupos minoritários, como das pessoas com deficiência, quando percebem que a organização em que trabalham valoriza a diversidade, tendem a ter atitudes positivas em relação à sua organização, ao trabalho e à carreira, gerando assim maior comprometimento por parte do empregado, maior satisfação com a empresa e melhor desempenho. Outra 
Estudo de caso sobre a inserção de pessoas com deficiência numa organização de grande porte

consequência positiva dos programas de diversidade é ter grupos com melhor desempenho e mais inovadores (HITT; MILLER e COLELLA, 2007).

\section{METODOLOGIA}

A metodologia utilizada foi a abordagem quantitativa e qualitativa. Embora historicamente tenha havido debate e contraposição sobre as duas abordagens, cada uma delas tem suas vantagens e contribuições (SERAPIONI, 2000). Além disso, para Minayo, Assis e Souza (2005), as duas abordagens podem ser usadas como complementares. Há que ser respeitado o rigor metodológico de ambas e exploradas ao máximo as ferramentas que elas desenvolveram ao longo dos anos.

$\mathrm{Na}$ abordagem quantitativa, foi realizado um survey com as pessoas com deficiência e seus respectivos gestores para se conhecer a percepção sobre o programa de inclusão da empresa. $\mathrm{Na}$ abordagem qualitativa, foram realizadas entrevistas, observação em campo e análise de documentos do programa.

A partir da utilização de diferentes métodos, é pretendida melhor e maior compreensão sobre os fenômenos estudados, investigando aspectos quantitativos que são relevantes, mas também realizando uma análise em profundidade, para permitir melhor compreensão dos dados. Ou seja, foi almejado fazer uma triangulação de métodos. "Quem propõe uma abordagem por triangulação de métodos quantitativos e qualitativos reconhece que na realidade a ser avaliada há processos que podem ser explicados em sua magnitude e compreendidos em sua intensidade" (MINAYO et al., 2005, p. 99).

O delineamento utilizado foi o estudo de caso, pois foi investigada uma grande organização do setor de mineração, para se conhecerem aspectos da inserção de pessoas com deficiência. O estudo de caso visa à investigação de um caso específico, bem delimitado, contextualizado em tempo e lugar, a fim de que se possa realizar uma busca circunstanciada de informações (VENTURA, 2007).

Uma das vantagens do estudo de caso em relação às demais estratégias metodológicas é permitir uma análise mais pormenorizada do seu objeto. Essa análise permite ao pesquisador obter resultados que não seriam acessíveis de outra forma, favorecendo, assim, a efetiva compreensão dos diversos elementos do caso em pauta. Outra característica interessante do estudo de caso é sua propriedade heurística, ou seja, sua capacidade de fomentar descobertas e criações (PERES e SANTOS, 2005).

REAd | Porto Alegre - Edição 78 - N² 2 - maio/agosto 2014 - p. 496-528 
O estudo foi realizado numa organização de grande porte, a qual implantou o programa de inclusão a partir de 2004. Conforme o Relatório de Sustentabilidade dessa organização (2010), a empresa preza pela ética em seus negócios, pela responsabilidade econômica, social e ambiental, bem como foca as pessoas. Ela possui no Brasil mais de 50.000 empregados próprios e tem o compromisso assumido junto ao Ministério do Trabalho e Emprego (MTE) de contratar anualmente pessoas com deficiência até garantir o preenchimento da cota estabelecida pela legislação. Suas unidades operacionais estão espalhadas nas várias regiões do Brasil. Sua dispersão geográfica, seu ramo de atividade (mineração) e a respectiva falta de acessibilidade das instalações, o rápido crescimento nos últimos anos, o nível de burocracia organizacional e falta de conhecimento dos gestores sobre inclusão, são desafios vivenciados por esta organização no tocante à inclusão.

Esta empresa possui políticas, processos e procedimentos de Recursos Humanos implantados, bem como valores organizacionais definidos e divulgados. Os processos de RH procuram refletir o que há de atual e moderno na área, tendo implantado, por exemplo: gestão de clima organizacional, gestão de desempenho, processo de carreira e sucessão, valorização do recrutamento interno, plano de cargos e salários, área definida para relações trabalhistas, universidade corporativa e ênfase no desenvolvimento das pessoas. $\mathrm{O}$ grande crescimento dessa organização nos últimos anos tem lançado um desafio para a área de RH de se modernizar constantemente e suportar o crescimento da empresa e suas necessidades, principalmente de mão de obra capacitada. Entre os valores da organização, existiu por determinado período de tempo, um valor específico chamado de "respeito à diversidade", o qual ajudou a colocar em pauta a discussão sobre as diferenças individuais e a necessidade do respectivo respeito. A discussão, por exemplo, sobre as pessoas com deficiência e sobre a participação das mulheres no trabalho, passou a fazer parte do universo corporativo.

A empresa é do setor de mineração, possui muitas unidades industriais em regiões remotas, afastadas dos grandes centros industriais, e uma grande dispersão geográfica. Além disso, esse ramo de negócio traz consigo determinado risco devido à quantidade de equipamentos que opera e ao fato de as condições de suas instalações serem mais rústicas. Uma parte das atividades desenvolvidas está em campo, em contato direto com a natureza. Devido a essas condições de trabalho desafiadoras, à falta de informações e ao preconceito existente de forma geral na sociedade, foi acreditado, por um tempo, ser impossível fazer a inserção de pessoas com deficiência nessa organização. O programa de inclusão da empresa 
Estudo de caso sobre a inserção de pessoas com deficiência numa organização de grande porte

compreendeu algumas fases, como: mapeamento de cargos, análise de acessibilidade, adaptação de infraestrutura e acessos, recrutamento e seleção, e sensibilização.

Conforme o Relatório de sustentabilidade de 2011 da organização, seus empregados estão distribuídos nas seguintes categorias: $75,2 \%$ são técnicos operacionais (operadores, técnicos etc.), $17,1 \%$ são especialistas (profissões que exigem uma formação de nível superior) e 7,7\% são gestores (supervisores, gerentes e diretores).

A população-alvo desta pesquisa foram as pessoas com deficiência que fazem parte dessa grande organização e foram contratadas até junho de 2011. Nessa data, a empresa pesquisada contava com 630 pessoas com deficiência em seu quadro de empregados. Foram excluídas da amostra as pessoas que não possuíam acesso a e-mail no ambiente de trabalho, pois isso dificultaria a coleta de dados com os mesmos. Assim, foram convidadas a participar da pesquisa 501 pessoas e houve resposta de 291 pessoas, o que corresponde a $58 \%$ da amostra. Foram considerados, também, os gestores das pessoas com deficiência. Houve adesão de 198 gestores, o que corresponde há 47\% da amostra.

$\mathrm{Na}$ coleta de dados, foi enviado um questionário por e-mail para as pessoas com deficiência e seus respectivos gestores, contendo perguntas abertas sobre a opinião das mesmas em relação ao programa de inclusão. Também foram incluídas perguntas sobre características sociodemográficas da população, a fim de se conhecer o perfil dos respondentes. Complementaram o estudo observações em campo, pesquisa de documentos e entrevistas semiestruturadas, para se conhecerem a percepção e a opinião das pessoas sobre a inclusão. A coleta de dados qualitativa envolveu um período maior, sendo realizadas cinco visitas a campo para observação em 2010 e 2011, durante alguns eventos de sensibilização e reuniões sobre o programa.

Foram utilizados nesta pesquisa como documentos os relatórios emitidos sobre o programa, comunicados realizados, relatório de sustentabilidade da organização, jornais da empresa e informações da coordenação do programa. Dessa forma, foram utilizados fontes confiáveis e documentos que foram compartilhados, seja internamente, no balanço social da empresa ou com o Ministério Público.

A análise qualitativa dos dados foi realizada utilizando-se o referencial da análise de conteúdo, o qual permite a compreensão da construção de significados que os atores sociais expressam em seus discursos.

Para Bardin (1977), é possível entender como análise de conteúdo: 
Um conjunto de técnicas de análise das comunicações visando obter, por procedimentos, sistemáticos e objetivos de descrição do conteúdo das mensagens, indicadores (quantitativos ou não) que permitam a inferência de conhecimentos relativos às condições de produção/recepção (variáveis inferidas) destas mensagens (p. 44).

A partir da comunicação expressa, é investigado, pela análise de conteúdo, o significado do enunciado, ou seja, é feita a interpretação das mensagens de forma que se revele um conhecimento novo sobre o que foi emitido.

\section{APRESENTAÇÃO E DISCUSSÃO DOS RESULTADOS}

\subsection{Histórico do programa de inclusão}

O programa de inclusão na organização pesquisada teve início em 2004, conforme divulgado no Relatório de Sustentabilidade dessa empresa. Foi assinado um termo de compromisso com o Ministério Público, no qual a empresa assumiu a obrigação de capacitar e contratar um determinado número de pessoas com deficiência por ano.

Nos anos de 2005, 2006 e 2007, ocorreram a contratação e a formação de pessoas com deficiência em três Estados diferentes, totalizando 209 contratações. Houve uma parceria com instituições especializadas para viabilizar a formação e o apoio ao programa. De acordo com o relatório apresentado pela consultoria que acompanhou o início do programa, algumas dificuldades percebidas nessa fase foram: riscos inerentes ao ambiente de trabalho que inviabilizam algumas deficiências - como cadeirantes e deficientes visuais -, instalações sem acessibilidade necessária às pessoas com deficiência, baixa escolaridade dos candidatos e falta de conhecimento dos profissionais da empresa (gestores, recursos humanos, segurança e medicina do trabalho) sobre as deficiências e de como lidar com elas.

Em 2008, foi realizado um aditivo ao termo de compromisso, no qual a empresa se comprometia a capacitar profissionalmente e contratar um mínimo de 140 pessoas por ano. Essa foi uma fase de maior mobilização e planejamento da empresa, para que houvesse o cumprimento do acordo junto ao MTE. O ano de 2009 foi, segundo os documentos identificados, um ano marcante de estruturação do programa, sendo o mesmo composto por: mapeamento de cargos para adequação às atividades da empresa, análise de acessibilidade, início da adaptação de infraestrutura e acessos, recrutamento e seleção de pessoas com deficiência, formação profissional, capacitação de profissionais da empresa (médicos, engenheiros de segurança, RH etc.), sensibilização e capacitação dos gestores, e análise para 
Estudo de caso sobre a inserção de pessoas com deficiência numa organização de grande porte

reabilitação de profissionais afastados em gozo de benefícios previdenciários. Em dezembro de 2009, foi criada a Política de Direitos Humanos da empresa, a qual reafirma o respeito à diversidade e não-tolerância à discriminação.

Foi observado que, nos primeiros anos do programa, houve segregação das pessoas com deficiência num mesmo cargo e salário. Os relatórios consultados indicaram que a maioria das pessoas com deficiência era contratada para o cargo de aprendiz operacional. Eram contratações por tempo determinado de um ano ou de seis meses, sendo, ao final do período, a depender de seu desempenho, avaliadas, a fim de verificar a mudança de contrato para prazo indeterminado na organização. Esse fato dificultou o recrutamento, a retenção e a satisfação das pessoas contratadas. A rotatividade dessas pessoas, nesse período, foi grande, além de gerar ansiedade e preocupação entre as pessoas com deficiência sobre sua permanência na empresa. Além disso, no início do programa, não houve a devida adequação e preparo da empresa para receber esses profissionais.

Foi a partir de 2010 que aconteceram alguns ajustes no programa visando à melhor gestão das pessoas com deficiência. É possível destacar que as contratações passaram a ser por prazo indeterminado e as pessoas passaram a ser geridas como as demais pessoas (mesmos critérios de avaliação de desempenho e treinamento).

$\mathrm{O}$ ano de 2011 foi marcado por continuidade nas ações visando à melhor acessibilidade, sensibilização e cumprimento da cota. Algumas ações que podem ser destacadas: implantação do Comitê de Inclusão e workshop nacional sobre o programa com os coordenadores de cada localidade, novos encontros de integração e avaliação do programa com as pessoas com deficiência, ações de sensibilização com RH e gestores em todos os Estados onde a empresa tem atuação, patrocínio do seminário sobre inclusão de pessoas com deficiência realizado pela Associação Brasileira de Medicina do Trabalho e capacitação dos médicos do trabalho.

Nos encontros realizados com as pessoas com deficiência no ano de 2011 pela empresa e observados para a realização da presente pesquisa (observações em campo), ficou evidente a maior satisfação com o programa e já não havia mais a preocupação com o contrato de prazo determinado (principal fator de insatisfação das pessoas que entraram nas cotas de 2008 e 2009). Entre os principais aspectos de satisfação com o programa, foram destacados: a qualificação profissional, a comunicação com os gestores, o contrato de trabalho ser por prazo indeterminado, o fato de trabalharem numa empresa de grande porte, a quebra de preconceitos na organização e a realização dos encontros anuais de integração. Como 
pontos de melhoria, foram citados: acessibilidade, comunicação com gestores, adequação de instrumentos e ferramentas de trabalho, algumas pessoas rotularem as pessoas com deficiência, preconceito e necessidade de maior divulgação do programa. Embora a comunicação entre empregado e gestor e o preconceito aparecerem tanto nos aspectos positivos como nos pontos de melhoria, essa aparente contradição mostra a diversidade da organização, o esforço para mudar as concepções de deficiência e que ainda coexistem essas diferentes realidades. Cabe ressaltar que predominaram nos encontros as falas dos aspectos positivos.

Conforme o Relatório de Sustentabilidade da empresa do ano de 2011, a próxima meta do programa seria eliminar as barreiras físicas da empresa, estando em estudo uma política de acessibilidade lançada em 2012. Essa política tem como desafio influenciar todos os planos e projetos da empresa, a fim de garantir que as medidas de acessibilidade sejam contempladas em todas as operações.

Dessa forma, é percebido que a empresa vem se adequando nos últimos anos para cumprir a legislação no tocante à contratação de pessoas com deficiência. Ficam evidenciadas as modificações realizadas, as reflexões realizadas pelos profissionais frente às dificuldades no processo de inclusão e a busca de construção de políticas internas que garantam o trabalho efetivo das pessoas com deficiência. Entretanto, é preciso concordar com Pereira (2011) que a inclusão é um processo em construção e, portanto, ainda há desafios a serem superados. $\mathrm{O}$ que ganha destaque nas observações é que a organização mostra-se aberta para refletir e ressignificar o tema inclusão e, gradativamente, tem realizado melhorias.

É possível perceber que o cumprimento da cota, nos primeiros anos um desafio com dificuldades para a sua realização, já passa a ser algo mais natural na organização, feito com planejamento e sendo superado antes do término do ano. Ou seja, a organização vem gradativamente se adequando e se empenhando para se tornar uma empresa inclusiva.

\subsection{Caracterização da amostra da pesquisa}

Participaram da pesquisa 291 pessoas com deficiência e 198 gestores. É necessário observar que prevalece na organização pessoas com deficiência do sexo masculino (68\%), com ensino médio completo (69\%) e do estado de Minas Gerais (37\%). A prevalência de pessoas do sexo masculino é similar à encontrada no mercado de trabalho. Na organização pesquisada, há grande prevalência de pessoas com deficiência física (86\%); no mercado formal, essa prevalência é de 54,47\%, conforme aponta a RAIS (MTE, 2010).

REAd | Porto Alegre - Edição 78 - N² 2 - maio/agosto 2014 - p. 496-528 
Estudo de caso sobre a inserção de pessoas com deficiência numa organização de grande porte

É possível observar que a maioria significativa das pessoas trabalha numa função administrativa ou operacional (85\%). Essas funções compreendem, por exemplo, os cargos de mecânico, eletricista, assistente administrativo etc. As funções de nível técnico (9\% das pessoas com deficiência ocupam esse tipo de função) compreendem aquelas que exigem formação técnica específica, como técnico em segurança, técnico em mineração e técnico em eletricidade. O grupo de profissionais no nível técnico profissional (5\%) compreende as funções que exigem curso superior, como analista, médico e engenheiro. Já o grupo de gestão são as funções que envolvem liderança de pessoas, como supervisor, gerente e diretor (nestas, encontra-se $1 \%$ do quadro de pessoas com deficiência). É observável, dessa forma, significativa predominância das pessoas com deficiência nos cargos administrativos e operacionais em detrimento, principalmente, dos cargos de gestão. Pesquisa feita pelo Instituto Ethos (2010) sobre o perfil social, racial e de gênero nas 500 maiores empresas do Brasil e suas ações afirmativas aponta que, nesse grupo de empresas, 97,6\% das pessoas com deficiência estavam no quadro funcional e apenas $2,4 \%$ no quadro de gestão. Ao se compararem esses dados com os da empresa pesquisada, é possível verificar que apenas 0,79\% das pessoas com deficiência estão no quadro de gestão. É constatada, assim, uma subrepresentação desses indivíduos, principalmente no quadro de gestão da organização, uma vez que esse quadro representa $7,7 \%$ do efetivo, conforme informa o Relatório de Sustentabilidade da empresa do ano de 2011. Estudo de caso realizado por Pereira (2011) numa organização de grande porte identificou apenas $1,2 \%$ de pessoas com deficiência em cargos gerenciais. Dessa forma, foi constatado que essa não é uma particularidade da empresa pesquisada, mas, como aponta a pesquisa do Instituto Ethos (2010), mesmo nas maiores empresas do Brasil, é baixa a representatividade dessas pessoas no nível gerencial.

Quanto ao tempo de casa, apesar de o programa ter sido iniciado em 2004 e as primeiras contratações terem ocorrido em 2005, são encontrados $18 \%$ do quadro de pessoas com deficiência com mais de seis anos de experiência nessa organização. Isso se deve aos reabilitados (25) e a outras contratações que ocorreram antes de 2005. Como o programa de inclusão é recente, é possível observar que a maioria das pessoas tem pouco tempo na empresa. Quanto à família do cargo, daquelas que estão inseridas em diferentes cargos, prevalece o número de pessoas na manutenção (34\%), em serviços (31\%) e na operação $(22 \%)$.

Entre os gestores que participaram da pesquisa, 83\% são do sexo masculino. Quanto à faixa etária, é notado que $50 \%$ têm menos de 40 anos e que praticamente $50 \%$ têm acima de 
40 anos. Prevalecem gestores dos estados de Minas Gerais (39\%), Espírito Santo (20\%) e Pará (18\%). Apenas $12 \%$ dos gestores não têm curso superior completo. Os demais possuem curso superior completo ou especialização.

No tocante à atuação profissional, 78\% informaram que já conviveram com pessoas com deficiência anteriormente. A grande maioria gerencia pessoas com deficiência física (75\%). Quanto ao tempo de experiência na empresa, $27 \%$ têm de seis a dez anos e $27 \%$ têm mais de 20 anos na empresa. Apenas $21 \%$ da amostra têm menos de cinco anos na empresa, prevalecendo um grupo de gestores com maior experiência. Quanto ao tempo em que ocupam o cargo atual, 62\% estão de um a cinco anos nesse cargo. Quanto ao tempo em que esses gestores trabalham diretamente com pessoas com deficiência, $67 \%$ informaram que trabalham de um a três anos e $17 \%$ de seis meses a um ano. A maioria dos gestores (58\%) considera que possui informações superficiais sobre as pessoas com deficiência.

\subsection{Percepções sobre o programa de inclusão}

O questionário aplicado nas pessoas com deficiência apresentava duas perguntas abertas. A primeira delas era: "Na sua opinião, quais os três principais pontos positivos do programa de inclusão da empresa?" As informações foram submetidas à análise de conteúdo, sendo que, para organizar e facilitar o entendimento, foi organizada uma Matriz de Agrupamento Temático. Essa Matriz consiste num quadro de resultados, organizado de acordo com a frequência das respostas. A Tabela 1 apresenta a Matriz de Agrupamento Temático dessa pergunta. As respostas foram organizadas em categorias e subcategorias para facilitar o entendimento e a compreensão.

Tabela 1 - Matriz de agrupamento temático com a opinião das pessoas com deficiência sobre os principais aspectos positivos do programa de inclusão

\begin{tabular}{|c|c|c|c|}
\hline Categoria & Subcategoria & $\mathbf{N}$ & $\%$ \\
\hline Oportunidade de trabalho & & 141 & 23 \\
\hline Consequências positivas do trabalho & & 133 & 22 \\
\hline \multirow{5}{*}{$\begin{array}{l}\text { Percepção da forma de tratamento } \\
\text { com as pessoas com deficiência } \\
(131 \text { respostas }=21 \%)\end{array}$} & Integração & 34 & 14 \\
\hline & Gestão do programa & 32 & 14 \\
\hline & Valorização & 26 & 11 \\
\hline & Respeito & 26 & 11 \\
\hline & Reconhecimento & 13 & 6 \\
\hline \multicolumn{2}{|c|}{$\begin{array}{l}\text { Inclusão (percepção das pessoas que mostram práticas inclusivas } \\
\text { - atitudes, valores, igualdade, aceitação) }\end{array}$} & 105 & 17 \\
\hline \multicolumn{2}{|l|}{ Capacitação } & 36 & 6 \\
\hline \multicolumn{2}{|l|}{ Benefícios } & 23 & 4 \\
\hline \multicolumn{2}{|l|}{ Orgulho de trabalhar nesta empresa } & 14 & 2 \\
\hline \multicolumn{2}{|l|}{ Outros } & 35 & 6 \\
\hline
\end{tabular}

REAd | Porto Alegre - Edição 78 - $\mathrm{N}^{\circ} 2$ - maio/agosto 2014 - p. 496-528 
Estudo de caso sobre a inserção de pessoas com deficiência numa organização de grande porte

Nota: $\mathrm{N}=$ Número de respondentes.

Fonte: os autores

Participaram da pesquisa 291 pessoas com deficiência. Na pergunta sobre os três principais aspectos positivos, foram obtidas 618 respostas. Em primeiro lugar, com maior número de respostas, foi apontado terem uma oportunidade de trabalho. Em segundo lugar, relataram as consequências positivas decorrentes do trabalho. Em terceiro lugar, colocaram a percepção da forma de tratamento, quando citam a percepção de integração, gestão que recebem na organização, valorização, respeito e reconhecimento.

Para 141 pessoas com deficiência, a oportunidade de trabalho é o principal aspecto positivo do programa de inclusão. Essa resposta mostra a importância do trabalho na vida das pessoas com deficiência que, por muito tempo, estiveram às margens das oportunidades e corrobora outras pesquisas na área (Carvalho-Freitas, Marques, \& Scherer, 2005; Pereira, Del Prette, \& Del Prette, 2008; Gomes, 2009; Carvalho-Freitas, Toledo, D’Ávila, Nepomuceno, Suzano, \& Almeida, 2010). O trabalho tem grande relevância na vida das pessoas com deficiência e contribui para a transformação da realidade de exclusão social, sendo essencial para a construção da identidade, o exercício da cidadania e o desenvolvimento socioemocional (Pereira et al., 2008; Gomes, 2009).

Para 133 pessoas com deficiência, as consequências positivas advindas do trabalho são o principal aspecto do programa de inclusão. Elas citam como consequências positivas: independência financeira, melhora da autoestima, satisfação, reconhecimento profissional e sentimento de ser útil e ser visto pela sociedade como um trabalhador. Pesquisa realizada por Vash (1988) aponta que as recompensas advindas do trabalho faz com que muitas pessoas com deficiência optem por um emprego ao invés de se manterem com os auxílios assistenciais. Essa mesma autora diz que o trabalho permite às pessoas terem recompensas internas, como: autorrealização, pertinência e autoestima; e, também, recompensas externas, como: poder, salário e prestígio. Pesquisa realizada por Pereira et al. (2008) sobre o sentido do trabalho para pessoas com e sem deficiência aponta que a valorização pessoal e profissional ocupou um lugar de destaque na opinião dos participantes da pesquisa, ressaltando também sua importância para o desenvolvimento socioemocional das pessoas com deficiência.

A terceira resposta mais frequente apontava para a percepção da forma de tratamento que receberam na organização, a qual envolveu 131 respostas. Essa categoria foi organizada em subcategorias, sendo composta pela percepção de integração, gestão do programa (a forma

REAd | Porto Alegre - Edição 78 - N 2 - maio/agosto 2014 - p. 496-528 
como os gestores lidam com as pessoas com deficiência e a coordenação em si do programa de inclusão, da transparência e do apoio da organização), percepção de valorização profissional, respeito e reconhecimento.

Uma constatação importante para a gestão da diversidade é quanto à forma como é o tratamento das pessoas e a disseminação de valores organizacionais coerentes com o respeito à diferença. Pesquisa realizada na Serasa aponta que essa instituição "obteve sucesso em seu processo de inclusão de pessoas com deficiência porque, antes disso, a sua gestão esteve centrada na pessoa e na disseminação de valores que favorecem a gestão da diversidade" (ÁVILA-VITOR, 2011, p. 174).

Uma quarta categoria foi composta pela resposta de 105 pessoas e revelou a adoção de práticas inclusivas pela organização, sendo apontada como ponto positivo do programa. Entre essas práticas, são citadas: a contratação de pessoas com diferentes formações, a diversidade de cargos em que estão trabalhando, a conscientização, não ter preconceito e discriminação com as pessoas com deficiência e o tratamento igualitário, entre outros. Outros fatores citados como aspectos positivos do programa de inclusão foram: a capacitação, os benefícios e o orgulho de fazerem parte dessa grande organização.

Foi perguntado para as pessoas com deficiência no questionário que receberam: "Em sua opinião, quais os três principais aspectos que podem ser aprimorados no programa de inclusão desta organização?" Houve 472 respostas, as quais foram categorizadas para melhor compreensão das mesmas e estão na Tabela 2.

Tabela 2 - Matriz de agrupamento temático com a opinião das pessoas com deficiência sobre os principais aspectos a serem melhorados no programa de inclusão

\begin{tabular}{llll}
\hline Categoria & $\mathbf{N}$ & $\boldsymbol{\%}$ \\
\hline Acessibilidade & 85 & 18 \\
\hline Oportunidade de crescimento & 73 & 15 \\
\hline $\begin{array}{l}\text { Melhor avaliação do perfil do profissional } \\
\text { limitações, formação, experiência) para se definir o cargo }\end{array}$ & & 10 \\
\hline Ações que expressam preconceito & 46 & 10 \\
\hline Divulgação & 45 & 10 \\
\hline Qualificação das pessoas com deficiência & 41 & 9 \\
\hline Remuneração e benefícios & 33 & 7 \\
\hline Acompanhamento das pessoas com deficiência & 31 & 7 \\
\hline Não vejo pontos a melhorar & 29 & 6 \\
\hline Recrutamento e seleção & 24 & 5 \\
\hline Sensibilização & 19 & 4 \\
\hline Integração & 16 & 3 \\
\hline Não categorizadas & 11 & 2 \\
\hline
\end{tabular}

REAd | Porto Alegre - Edição 78 - N 2 - maio/agosto 2014 - p. 496-528 
Estudo de caso sobre a inserção de pessoas com deficiência numa organização de grande porte

Fonte: os autores

A acessibilidade foi o principal aspecto apontado pelas pessoas com deficiência como fator de aprimoramento (85 considerações a esse respeito). De fato, nem todas as áreas da organização estão preparadas para recebê-las. Foram observadas: muitas escadas ou degraus em áreas comuns de acesso (restaurante, portaria, banheiros), falta de banheiros adaptados, falta de sinalizações apropriadas para as pessoas com deficiência visual e auditiva etc. Embora tenha sido feita a análise de acessibilidade por consultoria especializada na maioria das unidades, as adequações necessárias não foram realizadas em todas elas.

Para 73 pessoas com deficiência, o que pode ser aprimorado no programa é a oportunidade de crescimento profissional. Alguns têm a percepção de que sua qualificação profissional é superior à exigida pelo cargo que ocupa. Embora isso ocorra em algumas situações, outros fatores, como o desempenho, são avaliados pela organização para que o empregado seja promovido (o critério não é somente a escolaridade). Entretanto, esse é um ponto de atenção para que a organização avalie, pois as pessoas demonstram vontade de crescer e esperam ter oportunidade para tal. Estudo realizado por Carvalho-Freitas (2009), numa grande empresa do ramo de serviços e intermediação financeira com mais de 1.400 pessoas com deficiência contratadas, encontrou satisfação das pessoas com aspectos de qualidade de vida. Porém, no tocante à remuneração e oportunidades de crescimento profissional, encontrou insatisfação de $30 \%$ das pessoas com deficiência e que elas percebem diferenças no tratamento relacionado ao crescimento profissional. Para essa autora, isso pode refletir a coexistência na organização das concepções de normalidade e concepção espiritual, dando ênfase à deficiência como impedimento ao desempenho e crescimento. Pesquisa realizada por Pereira et al. (2008) também encontrou o fator falta de reconhecimento como item de insatisfação entre as pessoas com deficiência.

Uma melhor avaliação do perfil do profissional (possibilidades, limitações, formação) antes de se definir o cargo foi apontada por 46 pessoas como ponto de melhoria. Esse fato assinala a necessidade de treinamento dos profissionais da empresa e a necessidade de acessibilidade, o que foi ressaltado, também, pelos gestores e pelo profissional de RH. Segundo Pereira (2011), as empresas buscam adaptar as pessoas com deficiência ao trabalho, e quase nunca o contrário.

Para 45 pessoas com deficiência, o que pode ser aprimorado no programa são algumas práticas que evidenciam preconceito e discriminação. De acordo com Silva (2006), as pessoas com deficiência causam estranheza num primeiro contato, que pode manter-se ao longo do REAd | Porto Alegre - Edição 78 - N 2 - maio/agosto 2014 - p. 496-528 
tempo a depender do tipo de interação e dos componentes dessa relação. Como o corpo da pessoa com deficiência está fora dos padrões considerados adequados pela sociedade, ele é associado com a imperfeição humana. Há uma tendência a não aceitá-las porque se busca negar essa possibilidade de imperfeição, de inferioridade, de incompletude. Numa sociedade que prega a beleza, a produtividade, a previsibilidade e a perfeição a todo o momento e a todo custo, ver e conviver com alguém "imperfeito" ameaça a estabilidade psíquica. Por isso, ocorre a discriminação, o rótulo, numa tentativa de diferenciar e distanciar esse outro com o qual não se quer se identificar, pois está fora dos padrões ideais de beleza e produtividade.

Outros aspectos apontados como pontos a melhorar foram: a divulgação do programa, a qualificação profissional, salário e benefícios, acompanhamento e prática de feedback, o processo de recrutamento e seleção (demora), a integração (realização de eventos com outras pessoas com deficiência, receber mais informações sobre seu trabalho) e a sensibilização dos empregados e gestores.

Visando a conhecer a percepção em geral das pessoas com deficiência sobre o programa de inclusão, o questionário trouxe uma questão fechada a respeito desse tema, a qual é apresentada na Tabela 3.

Tabela 3 - Percepção das pessoas com deficiência sobre o programa de inclusão e de sua adaptação na empresa

\begin{tabular}{|c|c|c|c|}
\hline Pergunta & Escala & $\mathrm{N}$ & $\%$ \\
\hline Em sua opinião, o & $\begin{array}{l}\text { Está ótimo, a empresa tem incluído e integrado as } \\
\text { pessoas com deficiência }\end{array}$ & 88 & 31 \\
\hline $\begin{array}{l}\text { programa de Inclusão } \\
\text { de Pessoas com }\end{array}$ & $\begin{array}{l}\text { Está bom, esforços tem sido empreendidos e há } \\
\text { oportunidades de melhoria }\end{array}$ & 171 & 60 \\
\hline Deficiência: & $\begin{array}{l}\text { Está insatisfatório, há muitas oportunidades de } \\
\text { melhoria }\end{array}$ & 28 & 10 \\
\hline
\end{tabular}

Nota: $\mathrm{N}=$ Número de respostas.

Fonte: os autores

Ao analisar a Tabela 3, é possível perceber que 31\% das pessoas com deficiência avaliam o programa de inclusão como ótimo. Para 60\%, o programa está adequado. Elas reconhecem os esforços empreendidos e acreditam que há oportunidades de melhorias. Já para $10 \%$, o programa de inclusão está insatisfatório, acreditando que há necessidade de melhorias significativas.

Estudo de caso realizado numa organização de grande porte por Pereira (2011) relata que as adaptações que se procurou encontrar na organização estudada ficaram abaixo do 
Estudo de caso sobre a inserção de pessoas com deficiência numa organização de grande porte

esperado, principalmente no tocante à utilização de tecnologia. $\mathrm{O}$ autor menciona que as transformações na organização estão ocorrendo de forma gradual para se tornar uma empresa inclusiva, destacando que esse é um processo "em construção", no qual coexistem os paradigmas da inclusão, da integração e da exclusão. Esses resultados corroboram os achados desta pesquisa, como denunciam as pessoas com deficiência e os próprios gestores, conforme apresentado a seguir:

Este processo ainda se encontra cercado por estigmas, obedece a lógicas impostas pelo mercado capitalista, pelas políticas públicas, enfim, pelas barreiras culturais da empresa e da sociedade. Nesse sentido, as adaptações ainda não são passíveis de promover as mudanças paradigmáticas esperadas na inclusão das pessoas com deficiência (p. 132).

No questionário enviado aos gestores, foi perguntado sobre o programa de inclusão. A Tabela 4 apresenta a Matriz de Agrupamento Temático da pergunta "Qual sua opinião sobre o programa de inclusão da empresa?"

Tabela 4 - Matriz de agrupamento temático com a opinião dos gestores sobre o programa de inclusão

\begin{tabular}{|c|c|c|c|}
\hline Categoria & Subcategoria & $\mathbf{N}$ & $\%$ \\
\hline \multirow{8}{*}{$\begin{array}{l}\text { Aspectos positivos } \\
(137 \text { respostas }=76 \%)\end{array}$} & Percepção de ser muito bom o programa & 39 & 28 \\
\hline & $\begin{array}{l}\text { Quebra de paradigma (gerou aprendizagem, diminuiu } \\
\text { preconceito, valorização profissional) }\end{array}$ & 37 & 27 \\
\hline & Cria oportunidade para as pessoas com deficiência & 20 & 15 \\
\hline & Alinhamento aos valores da empresa & 18 & 13 \\
\hline & Evolução interna do programa & 11 & 8 \\
\hline & Bons profissionais com deficiência & 6 & 4 \\
\hline & Atendimento à legislação & 4 & 3 \\
\hline & Melhora a imagem da empresa & 2 & 1 \\
\hline \multirow{9}{*}{$\begin{array}{l}\text { Pontos a melhorar } \\
(44 \text { respostas }=24 \%)\end{array}$} & Acessibilidade & 11 & 25 \\
\hline & Ampliação das contratações & 8 & 18 \\
\hline & Capacitação das pessoas com deficiência & 5 & 11 \\
\hline & Divulgação do programa & 5 & 11 \\
\hline & Não expressou o que precisa melhorar & 4 & 9 \\
\hline & $\begin{array}{l}\text { Melhor avaliação da pessoa com deficiência para } \\
\text { definir cargo e local }\end{array}$ & 3 & 7 \\
\hline & Capacitar empregados para saber lidar & 3 & 7 \\
\hline & Preparo dos gestores para lidar & 3 & 7 \\
\hline & Melhor apoio do RH e gestores & 1 & 2 \\
\hline
\end{tabular}

Fonte: os autores 
Na pergunta feita aos gestores referente à opinião sobre o programa de inclusão, foram obtidas 181 respostas e houve a participação de 198 gestores. Foram identificadas duas categorias principais, sendo numa delas apresentadas respostas ressaltando aspectos positivos do programa (137 respostas) e na outra citados alguns aspectos a melhorar (44 respostas). Essa aparente dualidade ou contradição expressa bem o momento vivido pela organização no tocante à inclusão: se, por um lado, predominam aspectos positivos e a organização vem se empenhando para se tornar realmente inclusiva, por outro lado, até mesmo pelo pouco tempo em que existe o programa, foram observados aspectos que podem ser aprimorados. Estes dependem de tempo, de maior amadurecimento e aprendizado da organização e de todos os atores que a compõem (gestores, empregados com e sem deficiência, áreas de apoio do programa) se empenharem para recrutar, desenvolver e conviver com as pessoas com deficiência.

No tocante aos aspectos positivos do programa, 39 gestores expressaram a percepção de ser um bom programa ( $28 \%$ das respostas dos aspectos positivos).

A opinião de 37 gestores ressaltou a quebra de paradigma que ocorreu na empresa, destacando que a convivência com essas pessoas proporcionou aprendizado, diminuiu preconceito e houve valorização profissional dessas pessoas:

Proporciona novo olhar sobre o diferente, fazendo com que nos adequemos tanto física como socialmente (gestor 7).

Ótima oportunidade para as pessoas com deficiência se ingressar em uma grande empresa e ótima oportunidade dos funcionários conhecer e conviver com pessoas com deficiência (gestor 9).

Acredito que este programa tem apoiado muito na mudança de visão das pessoas sobre as pessoas com deficiência, abrindo portas para estas pessoas e também para nós gestores que não tínhamos conhecimento (gestor 66).

Uma oportunidade para romper o preconceito e promover a integração de pessoas capazes de desempenhar atividades como qualquer outra (gestor 42).

Pesquisa realizada por Ávila-Vitor (2011) em empresa referência na área de inclusão conclui "que a convivência é um grande aliado na minimização dos preconceitos em relação à deficiência, sendo ressaltada pelos gestores como o melhor treinamento para lidar com elas" (p. 174). Essa conclusão corrobora os resultados encontrados nesta pesquisa, reforçando a importância da convivência como fator capaz de gerar aprendizado e mudança de percepção. Outra contribuição relevante é relatada em pesquisa de Carvalho-Freitas e Marques (2009) ao REAd | Porto Alegre - Edição 78 - N 2 - maio/agosto 2014 - p. 496-528 
Estudo de caso sobre a inserção de pessoas com deficiência numa organização de grande porte

constatarem que, em empresas que têm investido na inclusão e buscam ser socialmente responsáveis, quanto mais tempo se convive com as pessoas com deficiência, melhor tende a ser a avaliação de seu desempenho. Ou seja, a convivência com as pessoas com deficiência impacta numa melhor avaliação de seu desempenho, diminui os preconceitos e gera um aprendizado sobre como lidar e conviver com as diferenças. A pesquisa realizada por Shannon et al. (2009) acrescenta que o tipo do contato, o contexto social e o poder que um indivíduo exerce pelo seu cargo ou posição podem influenciar significativamente as atitudes individuais e sociais para com as pessoas com deficiência. Assim, a depender dessas variáveis, as atitudes podem ser mais positivas ou mais negativas.

Para 20 gestores, a percepção da criação de oportunidades de contratação para as pessoas com deficiência foi o fator ressaltado na pergunta sobre os aspectos positivos do programa. Como a empresa tem um de seus valores o "respeito à diversidade", 18 gestores ressaltaram o alinhamento do programa com esse valor da empresa. A evolução interna do programa foi percebida por 11 gestores entre os aspectos positivos. Outros aspectos citados como pontos positivos do programa foram ter bons profissionais com deficiência, atendimento à legislação e melhoria da imagem da empresa.

A categoria dos aspectos a melhorar obteve 44 respostas, o que corresponde a $24 \%$ das respostas sobre a opinião a respeito do programa de inclusão. É apontada por 11 gestores a acessibilidade como principal aspecto a ser melhorado. Em seguida, a ampliação das contratações é assinalada por oito gestores. A capacitação dessas pessoas e a divulgação do programa estão na sequência na opinião de cinco gestores. Os demais fatores citados foram por um número pequeno de gestores (apenas três ou um supervisor): melhor avaliação das pessoas para se definirem o cargo e o local de trabalho, capacitar os empregados para saber lidar com as pessoas com deficiência, preparo dos gestores e melhor apoio da área de RH e gestores. De forma geral, os aspectos identificados pelos gestores são similares aos aspectos levantados também pelas pessoas com deficiência.

$\mathrm{Na}$ opinião dos gestores da empresa, é possível observar que prevalecem aspectos positivos do programa (76\% das respostas), destacando-se a quebra de paradigma ao lidar com as pessoas com deficiência, a geração de oportunidades e o alinhamento com os valores internos da organização. É apontada em $24 \%$ das respostas alguma oportunidade de melhoria, destacando a necessidade de acessibilidade, ou seja, a adequação da estrutura da empresa para conseguir receber todos os tipos de deficiência. Na fala dos gestores, foram observados erros 
e acertos nessa convivência e um desejo de ampliar o programa e tornar a empresa realmente inclusiva.

É percebido, dessa forma, que a organização tem procurado se adequar, vem cumprindo a cota estipulada pelo Ministério do Trabalho e que ainda tem alguns desafios a serem superados para se tornar uma organização realmente inclusiva. Os primeiros passos já foram dados, investimentos têm sido feitos e o assunto está inserido na rotina da organização (reuniões, treinamentos, indicadores). A organização, em menos de sete anos, tem evoluído rapidamente, mudando seu comportamento de exclusão (até 2004, não havia um programa estruturado) para a integração. A inclusão é um norte próximo a ser alcançado. O caminho é apontado pelos próprios gestores e profissionais com deficiência, conforme apresentado na análise de conteúdo.

\section{CONSIDERAÇÕES FINAIS}

A organização pesquisada, situada neste contexto histórico de transformação pela qual passa a sociedade, está vivenciando um movimento para se adequar e se tornar uma empresa inclusiva. De excludente até 2004, passou pelo movimento da segregação nos primeiros anos do programa (2005 a 2009), quando se definiram funções, locais, cargos e salários específicos para essas pessoas. Vivencia atualmente a fase de integração (2010 e 2011), na qual as pessoas, mediante sua competência e adaptação, têm mostrado que são capazes de produzir e gerar mudança nas práticas e valores da organização. Nesta fase, estão sendo criadas as condições para que possa haver um próximo avanço, que é ter uma fase realmente inclusiva. Embora no discurso da organização prevaleça o termo "programa de inclusão", é percebido, de acordo com a realidade encontrada, que esse é um desafio a ser alcançado e que os esforços têm sido empreendidos para tal.

Percebe-se uma quebra de paradigma na empresa, pois a contratação e convivência com as pessoas com deficiência proporcionaram aprendizado, diminuiu preconceito e houve maior valorização profissional dessas pessoas. Esse aprendizado advindo da convivência é ressaltado também por pesquisas realizadas por Carvalho-Freitas e Marques (2009) e ÁvilaVitor (2011). É possível certificar, dessa forma, que a convivência com as pessoas com deficiência, em situações de adequação das condições de trabalho, influencia a mudança de percepção das pessoas, beneficiando a integração, a percepção dos benefícios da contratação e a percepção de desempenho.

REAd | Porto Alegre - Edição 78 - N 2 - maio/agosto 2014 - p. 496-528 
Estudo de caso sobre a inserção de pessoas com deficiência numa organização de grande porte

Ficou evidenciada a importância do trabalho na vida dessas pessoas e seu impacto na transformação da realidade de exclusão social, o que ratifica pesquisas anteriores (CARVALHO-FREITAS et al., 2005, 2010; PEREIRA et al., 2008; PEREIRA, 2011). No tocante aos "principais pontos positivos do programa de inclusão", chama a atenção que a resposta mais frequente emitida pelas pessoas com deficiência foi ter uma oportunidade de trabalho. Nas falas das pessoas com deficiência, fica revelado que, por via do trabalho, elas deixam de ser invisíveis e passam a ser vistas pela sociedade. O olhar do outro que julga, discrimina e segrega muda para um olhar de reconhecimento pela capacidade laboral. Além disso, o olhar sobre si mesmas também se transforma. A estima parece ter sido roubada de si mesmas quando elas não têm um trabalho. Ao conquistá-lo, o olhar e o julgamento sobre si mesmas também são alterados, havendo maior valorização e a "devolução" da autoestima.

A seguir, são destacados, de forma sintética, alguns pontos importantes para subsidiar intervenções futuras ou para ratificar práticas já empregadas pela organização.

Como mais de $50 \%$ dos gestores afirmaram terem informações superficiais sobre as pessoas com deficiência, percebe-se que ainda há necessidade de se investir na formação e sensibilização dos gestores e demais empregados, para que possam ter maior conhecimento sobre como gerenciar as pessoas com deficiência. A informação pode contribuir para que invistam mais nas adequações necessárias, para que diminuam o desconhecimento e as resistências, para que valorizem mais o potencial desses profissionais e também pode contribuir para uma melhor socialização.

A prática de um estilo de gestão mais diretivo por parte dos gestores com as pessoas com deficiência pode contribuir para que tenham maior conhecimento dos seus objetivos profissionais, de suas prioridades e dos valores organizacionais, se sintam mais amparadas ou desafiadas a realizar um bom trabalho, contribuindo, assim, para a percepção de melhor integração à organização. O comportamento dos gestores mais diretivo é fundamental para que tenham uma boa socialização. Observou-se que nem todos os gestores adotam esse estilo, havendo queixas das pessoas com deficiência quanto à falta de apoio, de direcionamento e de feedback, principalmente nos primeiros anos do programa.

Possibilitar aos profissionais da organização situações de contato com pessoas com deficiência que sejam bem-sucedidas (seja profissionalmente, no esporte, na educação, cultura etc.) ou que estejam em posições de poder (líderes, professores) pode contribuir para minimizar as crenças negativas e o preconceito. Essa é uma constatação importante apontada por Shamon et al. (2009) de que o contato com pessoas com deficiência que estejam em 
situações de poder como líderes e professores é um fator relevante na formação de atitudes positivas em relação às pessoas com deficiência. Além disso, esse estudo mostra que um método eficaz para alterar as atitudes negativas relacionadas às pessoas com deficiência é fornecer novas informações que desafiam as crenças existentes.

O investimento na acessibilidade, como apontado pelos atores organizacionais, é fundamental para que as pessoas com deficiência tenham condições de exercer um bom trabalho, se comunicar, se locomover e, assim, diminuir as barreiras físicas e atitudinais. $\mathrm{O}$ estabelecimento de diretrizes de acessibilidade, instruções e metas específicas pode ajudar a diminuir as resistências e possibilitar maior agilidade nas adequações da organização. Além das adequações físicas, há necessidade de eliminação ou minimização das barreiras ligadas à comunicação.

O investimento em qualificação profissional das pessoas com deficiência pode auxiliálas na aquisição de conhecimentos técnicos e habilidades comportamentais fundamentais ao seu crescimento profissional. Ressalta-se a importância da abordagem de aspectos comportamentais que as auxilie a ter maior iniciativa, autonomia e segurança.

O diálogo sobre critérios de crescimento na organização, tipos de carreira, comportamentos e pré-requisitos necessários pode contribuir para o esclarecimento de dúvidas e sobre o caminho necessário ao crescimento. Não se pode menosprezar as dúvidas das pessoas com deficiência e reafirmar o tratamento igualitário. É necessário criar um espaço para informar e refletir sobre as oportunidades de crescimento e a carreira nesta organização.

Ficou evidenciada a importância do programa de ambientação no repasse de informações e facilitação da integração à organização. A prática de um programa de tutoria pode ser uma opção para que no dia a dia haja continuidade no repasse das informações (não existe essa prática padronizada em todas as regiões). A realização de eventos de integração (encontros, reuniões, rodas de conversa) é fundamental também para que possam se conhecer e expandir seus relacionamentos, tirar dúvidas, receber informações, falar de suas dificuldades e encontrar estratégias eficazes para terem acesso às informações da organização.

Assim, como a inclusão é um desafio a ser alcançado e diante dessa realidade na qual são necessárias mudanças significativas de comportamento social, pesquisas científicas como esta podem auxiliar as organizações a compreenderem melhor a diversidade que envolve o universo das pessoas com deficiência, podem contribuir para a adoção de estratégias mais eficazes e humanizadas na gestão da diversidade e podem auxiliar a subsidiar a formulação de políticas organizacionais que ajudem as empresas a terem práticas realmente inclusivas.

REAd | Porto Alegre - Edição 78 - N 2 - maio/agosto 2014 - p. 496-528 
Estudo de caso sobre a inserção de pessoas com deficiência numa organização de grande porte

Entre as contribuições deste estudo, pode-se constatar que: independente do ambiente, do setor em que atua e do porte da organização, é possível fazer a inserção de pessoas com deficiência. É vivida, no momento, uma fase de transição para um modelo realmente inclusivo (a sociedade e as organizações passam por essa transição). Há necessidade de constante investimento na reflexão e informação sobre as deficiências, para que se diminuam o preconceito e a exclusão social.

\section{REFERÊNCIAS}

ÁVILA-VITOR, M. R. C. A. Valores organizacionais e concepções de deficiência: A percepção das pessoas com deficiência. 2011. 202p. Dissertação (Mestrado em Psicologia), Universidade Federal de São João del-Rei, São João del-Rei, 2011.

BARDIN, L. Análise de conteúdo. Lisboa: Edições 70, 1977.

BARTALOTTI, C. C. Inclusão social das pessoas com deficiência: utopia ou possibilidade? São Paulo: Paulus, 2006.

BRASIL. Lei 8.213, de 24 de julho de 1991. Consolida a legislação que dispõe sobre os Planos de Benefícios e Custeio de Previdência Social e sobre a organização da Seguridade Social, e dá outras providências. Diário Oficial da União, Brasília, 14 ago. 1998. Disponível em <http://www.saci.org.br>. Acesso em: 15 de mar. 2010.

BRITE, R. B. Análise das concepções de gestores sobre deficiência em pessoas que ocupam postos de trabalho em uma rede de supermercados. 2009, 203p. Dissertação (Mestrado em Políticas Públicas e Formação Humana), Universidade do Estado do Rio de Janeiro, Rio de Janeiro, 2009.

CARUSO, A. Reverberações da Lei $\mathbf{n}^{\circ}$ 8.213/91 à luz das concepções de deficiência: Estudo de caso no contexto do projeto de sensibilização gerencial em uma organização privada de ensino profissionalizante. 2012, 260p. Tese (Doutorado em Políticas Públicas e Formação Humana), Universidade do Estado do Rio de Janeiro, Rio de Janeiro, 2012.

CARVALHO-FREITAS, M. N. A Inserção de pessoas com deficiência em empresas brasileiras - Um estudo sobre as relações entre concepções de deficiência, condições de trabalho e qualidade de vida no trabalho. 2007, 315p. Tese (Doutorado em Administração), Universidade Federal de Minas Gerais, Belo Horizonte, 2007. 
CARVALHO-FREITAS, M. N. Inserção e gestão do trabalho de pessoas com deficiência: Um estudo de caso. RAC, v. 13 (Edição Especial), p. 121-138, 2009.

CARVALHO-FREITAS, M. N.; MARQUES, A. L. A diversidade através da história: A inserção no trabalho de pessoas com deficiência. O\&S, v. 14, n. 41, p. 59-78, 2007.

CARVALHO-FREITAS, M. N.; MARQUES, A. L. Pessoas com deficiência e trabalho: Percepção de gerentes e pós-graduandos em administração. Psicologia, ciência e profissão, v. 29, n. 2, p. 244-257, 2009.

CARVALHO-FREITAS, M. N.; MARQUES, A. L. Inserção de pessoas com deficiência em organizações brasileiras: Um estudo com empresas socialmente responsáveis. Gestão Organizacional, v. 8, n.3, p. 483-502, 2010.

CARVALHO-FREITAS, M. N.; MARQUES, A. L.; SCHERER, F. L. Inclusão no mercado de trabalho: Um estudo com pessoas portadoras de deficiência. Revista de Práticas Administrativas, v. 1, p. 57-66, 2005.

CARVALHO-FREITAS, M. N.; TOLEDO, I. D’ÁVILA; NEPOMUCENO, M. F.; SUZANO, J. C. C.; ALMEIDA, L. A. D. Socialização Organizacional de pessoas com deficiência. RAE, v. 50, n. 3, p. 264-275, jul./set. 2010.

CUNHA, G. A. Dicionário etimológico. Rio de Janeiro: Fronteira, 1982.

DAUFEMBACK, V. Caso Embraco: Contribuindo para construção de uma sociedade inclusiva. In M. N. Carvalho-Freitas, \& A. L. Marques (Orgs.). Trabalho e pessoas com deficiência: pesquisas, práticas e instrumentos de diagnóstico. Curitiba, Juruá, 2009, cap. 14 , p. 218-228.

FÁVERO, E. A. G. Direito das pessoas com deficiência: Garantia de igualdade na diversidade. Rio de Janeiro: WVA, 2004.

GOMES, J. F. B. Contribuições da categoria trabalho para a formação da identidade da pessoa com deficiência. 2009. 125p. Dissertação (Mestrado em Psicologia), Pontifícia Universidade Católica de Minas Gerais, Belo Horizonte, 2009.

HITT, M. A.; MILlER, C. C.; COLELlA, A. Comportamento organizacional: uma abordagem estratégica. Rio de Janeiro, LTC, 2007. 
Estudo de caso sobre a inserção de pessoas com deficiência numa organização de grande porte

IGNARRA, C., CONTRI, T., \& BATHE, R. Inclusão: conceitos, histórias e talentos das pessoas com deficiência. Rio de Janeiro: Qualitymark, 2009.

INSTITUTO ETHOS. Perfil social, racial e de gênero das 500 maiores empresas do Brasil e suas ações afirmativas. São Paulo, 2010.

LARA, G. B., ÁVILA, M. R. C., \& CARVALHO-FREITAS, M. N. A questão cognitiva e afetiva na inserção das pessoas com deficiência no mercado de trabalho. Psicologia em Pesquisa, v. 2, n. 1, p. 46-59, 2008.

MINAYO, M. C. S., ASSIS, S. G., SOUZA, E. R., CONSTANTINO, P., \& SANTOS, N. C dos. Métodos, técnicas e relações em triangulação. In M. C. S. Minayo, S. G. Assis, \& E. R. Souza (Orgs.). Avaliação por triangulação de métodos: Abordagem de programas sociais. Rio de Janeiro: Fiocruz, 2005, p. 71-104.

MINISTÉRIO DO TRABALHO E EMPREGO. Características do emprego formal segundo a Relação Anual de Informações Sociais. Disponível em: <http://www.mte.gov.br/rais/2010/arquivos/Resultados_Definitivos.pdf>. Acesso em: 1 jun. 2012.

NERI, M., PINTO, A., SOARES, W., \& COSTILHA, H. Retratos da deficiência no Brasil. Rio de Janeiro: FGV/IBRE, 2003.

OLIVEIRA, E. R. Ações de Inclusão de funcionários com deficiência em empresas de diferentes ramos de atividades. 2008. 83p. Dissertação (Mestrado em distúrbios do desenvolvimento), Universidade Presbiteriana Mackenzie, São Paulo, 2008.

ORGANIZAÇÃO INTERNACIONAL DO TRABALHO. Dia Internacional das Pessoas com Deficiência: OIT pede mais ações para apoiar a integração das pessoas com deficiência no mundo do trabalho. Brasília. 2007. Disponível em: <http:www.oitbrasil.org.br/news/nov/>. Acesso em: 7 jul. 2011.

PASTORES, J. Oportunidades de trabalho para portadores de deficiência. São Paulo: LRT, 2000. Disponível em: < http://www.josepastore.com.br/artigos/index.htm> Acesso em: 10 fev. 2010.

PEREIRA, A. C. C. Inclusão de pessoas com deficiência no trabalho e o movimento da cultura organizacional: Análise multifacetada de uma organização. 2011. 161p. Dissertação (Mestrado em Educação), Universidade Federal do Rio Grande do Sul, Porto Alegre, 2011. 
PEREIRA, C. S.; DEL PRETTE, A.; DEL PRETTE, Z. A. P. Qual o significado do trabalho para as pessoas com e sem deficiência física? Psico-USF, v. 13, n. 1, p. 105-114, jan/jun 2008.

PERES, R. S.; SANTOS, M. A. Considerações gerais e orientações práticas acerca do emprego de estudos de caso na pesquisa científica em psicologia. Interações, v. 10, n. 20, p. 109-126, 2005.

RIBEIRO, M. A.; RIBEIRO, F. Gestão organizacional da diversidade: Estudo de caso de um programa de inclusão de pessoas com deficiência. In M. N. Carvalho-Freitas, \& A. L. Marques (Orgs). Trabalho e pessoas com deficiência: pesquisas, práticas e instrumentos de diagnóstico. Curitiba, Juruá, 2009, cap. 7, p. 122-141.

SASSAKI, R. K. Inclusão: Construindo uma sociedade para todos (7a ed.). Rio de Janeiro: WVA, 2006.

SERAPIONI, M. Métodos qualitativos e quantitativos na pesquisa social em saúde: Algumas estratégias para a integração. Ciência e Saúde Coletiva, v. 5, n. 1, p. 187-192, 2000.

SERRANO, C.; BRUNSTEIN, J. Competências dos gestores frente à inclusão da pessoa com deficiência: Os desafios da diversidade na organização. Rio de Janeiro: ENANPAD, 2008 .

SHANNON, C. D.; TANSEY, T. N.; SCHOEN, B. The effect of contact, context, and social power on undergraduate attitudes toward persons with disabilities. Journal of Rehabilitation, v. 75, n. 4, p. 11-18, 2009.

SILVA, L. M. O estranhamento causado pela deficiência: preconceito e experiência. Revista Brasileira de Educação, v. 11, n. 33, p. 424-434, 2006.

STAIMBACK, S.; STAINBACK, W. Inclusão: Um guia para educadores. Porto Alegre: Artes Médicas, 1999.

SUZANO, J. C. C.; NEPOMUCENO, M. F.; ÁVILA, M. R. C.; LARA, G. B.; CARVALHOFREITAS, M. N. Análise da produção acadêmica nacional dos últimos 20 anos sobre a inserção da pessoa portadora de deficiência no mercado de trabalho. In M. N. CarvalhoFreitas, \& A. L. Marques (Orgs.). O trabalho e as pessoas com deficiência: pesquisas, práticas e instrumentos de diagnóstico. Curitiba: Juruá, 2008, cap. 1, p. 23-42. 
Estudo de caso sobre a inserção de pessoas com deficiência numa organização de grande porte

VASH, C. L. Enfrentando a deficiência: a manifestação, a psicologia, a reabilitação. São Paulo: Pioneira, 1988.

VENTURA, M. M. O Estudo de caso como modalidade de pesquisa. Rev. SOCERJ, v. 20, n.5, p. 383-386, 2007. 